\title{
LA REGULACIÓN DE LA RECTIFICACIÓN REGISTRAL DE LA MENCIÓN RELATIVA AL SEXO DE LAS PERSONAS EN ESPAÑA
}

\section{Rosa María RICOY CASAS}

Esta Ley ${ }^{1}$ tiene por objeto regular los requisitos necesarios para acceder al cambio de la inscripción relativa al sexo de una persona en el Registro Civil, cuando dicha inscripción no se corresponde con su verdadera identidad de género. Muchos medios de comunicación han utilizado las imprecisas denominaciones de "ley de identidad de género" o de "identidad sexual", 2

1 Ley 13/2007, de 15 de marzo. Se dicta precisamente al amparo de esta competencia del Estado (artículo 149.1.8, CE), tal como nos indica su Disposición final primera. Cabe señalar que pese a su inicial paralización, ha podido advertirse que la fuerza de los hechos se ha impuesto, teniendo en cuenta las numerosas iniciativas legislativas en este sentido desde 1999, como las que a título ejemplificativo señalo a continuación: el 16 de febrero de 1999 el Grupo Parlamentario Federal de Izquierda Unida presentó una proposición no de ley por la que se instaba al gobierno a dictar disposiciones legales sobre el derecho de los transexuales a un cambio de sexo. El 22 de julio de 1999 el Grupo Socialista Parlamentario presenta en el Senado una proposición de ley sobre el derecho a la identidad sexual (proposición de ley 622/000017) publicada en el Boletín Oficial de las Cortes Generales del Senado, VI Legislatura, serie IIIA, núm. 17 (a), del 27 de julio de 1999. Otra por el mismo grupo el 20 de octubre 1999, y el 7 julio del 2000 en la VII Legislatura (proposición 622/000006) publicada en el Boletín Oficial del Senado VII Legislatura, serie IIIA, núm. 8 (a). Asimismo el 21 de diciembre de 2000 (proposición de ley 124/000001) que se publica en el Boletín Oficial de las Cortes Generales del Congreso de los Diputados, VII Legislatura, serie B, núm. 124-1, del 23 de marzo de 2001.

2 Puede objetarse que puede hacer pensar en lo sexual como expresión de lo genital, cuando la transexualidad no es un problema que tenga que ver con la sexualidad del sujeto, sino exclusivamente con la situación que genera la inadecuación física con la sensación íntima de pertenecer al sexo opuesto del que genéticamente se conformó. 
"disforia de género"3 o "disforia sexual", aunque muchos no comparten dicha concepción al entender que se trata de otro tipo de identidad fuera de convencionalismos.

Como precisión inicial, ha de señalarse que la palabra "sexo" generalmente se usa para hacer alusión a las diferencias biológicas relacionadas con la reproducción y otros rasgos físicos y fisiológicos entre los seres humanos. El sexo, como parámetro para crear categorías, distingue entre hombres y mujeres, entre machos y hembras de la especie humana. "Género" se refiere, sin embargo, a las características que socialmente se atribuyen a las personas de uno y otro sexo, diferencias por tanto de origen social, educativo, cultural, etcétera. En síntesis, podría definirse como la construcción sociocultural de esa diferencia. Los atributos de género son, entonces, femeninos o masculinos, y esa construcción (el género) no es inocente ni neutral, obedece a unos determinados intereses estructurales. Por lo tanto, una cosa son las diferencias biológicamente dadas, y otra la significación que culturalmente se asigna a esas diferencias. Comparto con Buttler cuando efectúa una reconstrucción de la dicotomía sexo/género, mostrando cómo el sexo es ya de por sí una construcción social que, por tanto, ha sido género todo el tiempo. ${ }^{4}$

En tal sentido, resulta muy ejemplificador cómo la "drag" (travesti) se siente más mujer que las propias mujeres, y reproduce la categoría de mujer tan fielmente, tanto, que no deja de desplazarla, puesto que existe un "fallo" en su cuerpo, en el que no dejan de recordarse atributos de hombre. El hecho de que, sin embargo, se pueda interpretar tan fielmente la categoría de mujer no deja de sugerirnos, que quizás ser mujer sea tan sólo una máscara, y es que necesitamos performar continuamente (representar, interpretar) nuestras categorías sexo/género. Para finalizar con estas cuestiones, cabe mencionar que el concepto de género se introdujo en la teorización feminista en los años setenta (1970). ${ }^{5}$

3 Artículo 4.1.a) y Disposición final segunda punto 4 en relación con la nueva redacción del artículo 93.2, Ley Registro Civil.

4 Buttler, J., El género en disputa. El feminismo y la subversión de la identidad, México, Paidós, 2001. Habría que preguntarse entonces ¿por qué le llaman género cuando quieren decir sexo? Este es el caso del propio título de Gil Rodríguez, E. P., “¿Por qué le llaman género cuando quieren decir sexo? Una aproximación a la teoría de la performatividad de Judith Butler", Atenea Digital, núm. 2, 2002.

5 Tubert, S. (ed.), Del sexo al género. Los equívocos de un concepto, Madrid, Cátedra, 2003, p. 7. 
Aunque sexólogos, sicólogos y médicos americanos ya lo habían utilizado en los años cincuenta (1950) con la intención de distinguir el sexo anatómico del género social, y solucionar así las dificultades conceptuales y terminológicas que planteaban los intersexos, transexuales y homosexuales cuyo sexo biológico era ambiguo al nacimiento, o no coincidía con su identidad sexual deseada u orientación sexual. Verena Stolke ha afirmado que son las feministas Kate Millet y Germaine Greer las primeras en emplear la noción sicoanalítica de género social en sus críticas políticas de las doctrinas bio-ideológicas occidentales acerca de la subordinación de las mujeres, quienes a su vez citan la obra del sicoanalista estadounidense Robert Stoller, "Sex and Gender" de 1968, como fuente del término "gender". 6

Quizás esta idea ya fue una intuición esbozada en la expresión de que "no se nace, sino que se deviene mujer" que Simone de Beauvoir había expresado ya en 1949 en su clásica obra titulada "el segundo sexo". ${ }^{7}$ El sexo es una realidad múltiple configurada por varios factores: el componente genético o cromosomático (XX para la mujer y XY para el hombre); el componente morfológico (órganos genitales); y el componente sicosocial (género masculino o femenino). Como señala Arantza Campos, los dos primeros tan sólo son "presuntivos" del último y más importante. ${ }^{8}$

Hasta hace poco eran presentados como enfermos. Baste recordar la ley de vagos y maleantes de la época franquista ${ }^{9}$ modificada en 1954 para incluir la represión de los homosexuales, ${ }^{10}$ sustituida en 1970 por la

6 Stolke, V., "La mujer es puro cuento: la cultura del género", Estudos Feministas, Florianópolis, 12 (2), mayo-agosto de 2004, pp. 77, 84, 85 y 86 y la obra citada de Stoller, R. J., Sex and Gender, Nueva York, Science House, 1968.

7 Beauvoir, S., El segundo sexo, Madrid, Cátedra-Instituto de la Mujer, 2000.

8 Campos, A., "La transexualidad y el derecho a la identidad sexual", ponencia presentada en Valencia, 2001.

9 Ley del Código Penal español de 4 de agosto de 1933 aprobada por consenso de todos los grupos políticos de la segunda república y conocida popularmente como "la Gandula", fue publicada en la Gaceta de Madrid, núm. 217, el 5 de agosto de 1933.

10 Ley de 15 de julio de 1954 por la que se modifican los artículos 2o. y 6o. de la Ley de Vagos y Maleantes de 4 de agosto de 1933. En el articulo segundo, número segundo, se expresa: "los homosexuais, rufianes y proxenetas", y el artículo sexto, número segundo, se expresa: "a los homosexuales, rufianes y proxenetas, a los mendigos profesionais y a los que vivan de la mendicidad ajena, exploten menores de edad, enfermos mentais o lisiados, se les aplicarán, para que las cumplan todas sucesivamente, las medi- 
ley sobre peligrosidad y rehabilitación social que incluía penas de internamiento en establecimientos de reducación o la prohibición de residir en determinados lugares. ${ }^{11}$ Sobre esta cuestión cabe reseñar que el Estado ha concedido en el año 2009 la primera indemnización a un homosexual por ser encarcelado durante el franquismo durante noventa y cuatro días en prisión, por una cantidad de 4000 euros.

Esta nueva Ley vino a colmar una de las demandas más insistentes del colectivo transexual, aunque muchos la han calificado de corto alcance, pues entre otras cuestiones no se trata de una ley integral sobre los transexuales que aborde más problemas que el aquí suscitado. Tampoco se dice nada de los intersexuales y los hermafroditas, y constituye una medida poco innovadora, que sigue los antecedentes de numerosos países europeos que desde hace más de treinta años se hicieron sensibles a esta necesidad. Así, Suecia fue la pionera en 1972 al establecer una "Ley sobre determinación del sexo en casos establecidos", ${ }^{12}$ a continuación Alemania en 1980 "sobre el cambio de nombre y sobre la determinación de la pertenencia sexual en casos particulares, ${ }^{13}$ y muchos otros países como Italia (1982), Holanda (1985), ${ }^{14}$ etcétera. Sensibilidad que trascendió al seno de las Instituciones Europeas en varias Resoluciones y Recomendaciones. ${ }^{15}$

das siguientes: a) internado en un establecimiento de trabajo o colonia agrícola. Los homosexuais sometidos a esta medida de seguridad deberán ser internados en instituciones especiais y, en todo caso, con absoluta separación de los demás; b) prohibición de residir en determinado lugar o territorio y obligación de declarar su domicilio; c) sumisión a la vigilancia de los delegados".

11 Ley 16/1970, del 1o. de agosto sobre peligrosidad y rehabilitación social publicada en el $B O E$, núm. 187, del 6 de agosto de 1970.

12 Ley de 21 de abril de 1972.

13 Ley de 10 de septiembre de 1980.

14 Asimismo otras como la Ley Belga de 10 de mayo de 2007: "Loi relative à transsexualité", Reino Unido mediante la Gender Recogniticon Act, sancionada el 1o. de julio de 2004, e incluso la Ley Japonesa de Identidad de Género que entró en vigor el 16 de julio de 2004, noticia difundida por el diario El Mundo y disponible en http: //www.figinternet.org/printarticle22.html, entre muchas otras.

15 Resoluciones del Parlamento y del Consejo de Europa en 1989 (Diario Oficial de las Comunidades Europeas, del 9 de octubre de 1989, p. 33); Resolución de 12 septiembre 1989 (Doc. A. 3-16/89 DOCE C 256, de 9 de octubre del Parlamento Europeo); Recomendación núm. 1117 adoptada el 29 de septiembre de 1989. Consejo de Europa, Estrasburgo (CJ-FA (91) 2), etcétera. 
Es más, desde la óptica de los derechos fundamentales, podría objetarse su tardanza, pues entre las principales finalidades señaladas por la ley en su exposición de motivos, se trata con la misma garantizar el libre desarrollo de la personalidad y la dignidad de estas personas, un derecho establecido en el artículo $10 \mathrm{CE}$, pero también el artículo $15 \mathrm{CE}$ donde se establece el derecho a la integridad sicofísica, el derecho a la intimidad y la propia imagen del artículo $18 \mathrm{CE}$, el artículo $14 \mathrm{CE}$ referido al derecho a la igualdad y la prohibición de discriminación por razón de sexo, e incluso, el artículo 43.1 CE donde se refleja el derecho a la protección de la salud. Y es que la salud no ha de definirse de una manera tan simple como sinónimo de no padecer enfermedad, sino más genéricamente, en el disfrute de un bienestar general, síquico-mental y social, que ayude a un pleno desarrollo personal. ${ }^{16}$

16 Como puede observarse, la mayoría de los mencionados son derechos fundamentales (incardinados en los artículos 14-29 y 30.2 CE). Según Pérez Luño, los derechos fundamentales constituyen la principal garantía con la que cuentan los ciudadanos de un Estado de derecho de que el sistema jurídico y político en su conjunto se oriente hacia el respeto y promoción de la persona humana; en su estricta dimensión individual, Estado liberal de derecho, o conjugando ésta con la exigencia de solidaridad, corolario del componente social y colectivo de la vida humana, Estado social de derecho: Pérez Luño, A. E., Los derechos fundamentales, Madrid, Tecnos, 1991, p. 20. Precisamente ostentan una garantía reforzada, en virtud del art. 53.2 CE para su reconocimiento ante los tribunales ordinarios por un procedimiento basado en los principios de preferencia y sumariedad y, en su caso, a través del recurso de amparo ante el Tribunal Constitucional, su vinculación a todos los poderes públicos, el que sólo puedan ser regulados y desarrollados por ley que en ciertos supuestos debe ser orgánica y que, en todo caso, ha de respetarse su contenido esencial, o acudir a la Institución del Defensor del Pueblo en virtud del artículo 54 CE. De otro modo, siguiendo a Prieto Sanchís, cualesquiera que sean los concretos medios de tutela previstos por cada ordenamiento, cuando el sistema de derechos fundamentales no ofrece al titular la posibilidad de obtener su satisfacción frente a los sujetos obligados, no cabe hablar en rigor de una verdadera existencia jurídica de derechos: Prieto Sanchís, L., "El sistema de protección de los derechos fundamentales: el artículo 53 de la Constitución Española", Anuario de Derechos Humanos, núm. 2, 1983, p. 370. Así, se cual fuere la modalidad de Estado, el catálogo de derechos y libertades que la Constitución incorpora es la expresión de la reserva de poder que se hace la sociedad a sí misma y en la que no puede entrar el legislador ordinario. Están por encima de la democracia, fuera del pluralismo y del debate político porque son exigencia de la dignidad de cada ser humano. De esta manera, la propia Constitución puede regularlos, concretarlos o desarrollarlos, pero en ningún caso desconocerlos, limitarlos o vaciarlos. Es más, en este caso concreto, si el límite lo pusiéramos en los derechos de los demás y el orden público, no habría nada que objetar, aun así no habría problema. 
En este contexto hay que incardinar la necesidad de tratamiento médico de las personas transexuales, pero sólo si ellos así lo estiman, pues comparto su rechazo a considerarlos enfermos. Si recurren al sistema sanitario no lo hacen porque se sientan enfermos, sino para que se les restituya su "verdadero cuerpo", para "corregir un error de la naturaleza". Cuestión que abre la, no por indiscutible poco polémica, necesidad de sufragar a través del Sistema Nacional de Salud todos sus tratamientos, incluida la cirugía, en el caso de que se decida por esta vía. ${ }^{17}$ De otra manera, en ciertos casos tales situaciones derivarían en marginación social y en la automedicación sin control, al no poder sufragar el alto coste de algunos tratamientos. Y es que, como ha manifestado Becerra Fernández, a diferencia de los travestidos, que alivian su conflicto vistiendo y comportándose como el sexo contrario, los transexuales necesitan adaptar su cuerpo al sexo opuesto al que se sienten pertenecer. ${ }^{18}$

En España, desde que el Servicio Andaluz de Salud inició la prestación sanitaria pública para la atención integral de los pacientes transexuales en 1999, ${ }^{19}$ y hasta octubre de 2004, solicitaron asistencia 421 transexuales, de los cuales el $17 \%$ procedían de otras comunidades autónomas. Tras la evaluación diagnóstica, fueron excluidos del protocolo de reasignación un $7 \%$ de los casos. ${ }^{20}$ Actualmente el Sistema Nacional de Salud no incluye en su cobertura sanitaria el tratamiento integral de reasignación de sexo, aunque algunas comunidades autónomas han decidido asumirlo por su cuenta, siendo el resultado de esta discrecionalidad pú-

17 Solicitud en la propia tramitación parlamentaria de la Ley 3/2007 a través de la intervención de la representante del G.P. IU-ICV en la Comisión de Justicia del Congreso Cortes Generales, Diario de Sesiones del Congreso de los Diputados, Comisión de Justicia, 7 de noviembre de 2006, núm. 696, p.11; Cortes Generales, Diario de Sesiones del Congreso de los Diputados, Pleno y Diputación Permanente, del 1o. de marzo de 2007, p. 11914.

18 Entre otras, Becerra Fernández, A., "Atención endicronológica de la transexualidad”, en García Ruiz, M. (coord.), Seminario Transexualidad: hombres y mujeres con todos los derechos. Guía sobre la transexualidad, Principado de Asturias, 2005, p. 99; disponible en http://www.cmpa.es/datos/2/GUIA_TRANSEXUALIDAD_interior_7529.pdf.

19 Unidad de Trastornos de Identidad de Género en el Hospital Universitario "Carlos Haya" de Málaga — el primero de España-.

20 Esteva, I. y otros, "Epidemiología de la transexualidad en Andalucía, atención especial al grupo de adolescentes", Cuadernos de Medicina y Psicomática y Psiquiatría de Enlace, núm. 78, 2006. 
blica, la acentuación de desigualdades. ${ }^{21}$ Necesidad puesta de manifiesto por el Tribunal Europeo de Derechos Humanos en una sentencia de 2007.22 Algo que ya había manifestado la Unión Europea en 1989 al instar a los Estados a su realización, ${ }^{23}$ siendo una realidad ya en Holanda, Suecia, Noruega y Reino Unido. ${ }^{24}$

No obstante, pese a las señaladas demoras y aun no colmadas todavía insatisfacciones, es una ley bien recibida y que muestra el proceso de largo aliento que ha de realizarse para enfrentarse con responsabilidad y eficacia a los desafíos y prioridades que cada periodo histórico supone, lo que traducido en palabras de Ollero, aplicable a cualquier necesidad jurídico-social (y que aquí utilizo en este ámbito), consiste en no conformarse con constatar simplemente que los tiempos cambian que es una barbaridad; es preciso advertir en qué medida esa transformación de las circunstancias vacía o potencia la finalidad que la medida perseguía, o altera la proporcionalidad de los medios previstos al efecto. ${ }^{25}$

Tal vez una medida demorada hasta la actualidad por la imposibilidad hasta fechas recientes de que se pudieran casar dos personas del mismo sexo, ${ }^{26}$ las cuestiones relativas a la filiación ${ }^{27}$ y otras como el servicio

21 Un paciente en Andalucía puede tener acceso a una operación de cambio de sexo y en Navarra y País Vasco desde hace diez años se cubre la atención dental infantil: http://www.web-salud.com de 4 de octubre de 2006. No obstante, puede haberse solucionado recientemente con el acuerdo alcanzado en el Consejo Interterritorial de Sanidad, el 12 de diciembre de 2007, al fijar los criterios para acreditar tres centros de referencia para el conjunto del Estado al que podrán acudir los interesados de cualquier comunidad, siendo los gastos de cargo de su propia comunidad (ABC, 13.12.2007, p. 28), con lo que se pondrá fin a la situación de desigualdad generada por las comunidades autónomas que ya lo financiaban.

22 Sentencia del TEDH de 11 de septiembre de 2007. TEDH: caso Goodwin vs. Reino Unido, Van Kück vs. Alemania y Grant vs. Reino, sentencia de 11 de septiembre de 2007 (caso L. vs. Lituania, TEDH 2007/56).

23 Resolución de 12 de septiembre de 1989.

24 Bustos Moreno, Y. B., La transexualidad (de acuerdo a la Ley 3/2007, de 15 de marzo), Madrid, Dykinson, 2008, pp. 90 y 91.

25 Ollero, A., Discriminación por razón de sexo. Valores, principios y normas en la jurisprudencia constitucional española, Madrid, Centro de Estudios Políticos y Constitucionales, 1999 , p. 80.

26 Ley 13/2005, de 1o. de julio, por la que se modifica el Código Civil en materia de derecho a contraer matrimonio.

27 La Ley 13/2005, de 1o. de julio, por la que se modifica el Código Civil en materia de derecho a contraer matrimonio, superó, al menos indirectamente, este problema al re- 
militar, el internamiento penitenciario, ${ }^{28}$ las propias relaciones laborales, etcétera. No deja por ello de asombrarnos que otras situaciones relacionadas con el otorgamiento del Documento Nacional de Identidad español, sin embargo, no hayan sido tan restrictivas ni tan polémicas. Me refiero a la normativa española que regula las características de las fotografías que se han de incluir en el DNI, la cual exige que el titular vaya con la cabeza destapada, ${ }^{29}$ e idéntica disposición se incluye entre los requisitos para la obtención del pasaporte..$^{30}$ Pese a que la literalidad de la norma habría de conducir a que la administración rechazase las fotografías de mujeres musulmanas que, por motivos religiosos o tradicio-

gular el matrimonio entre personas del mismo sexo, por lo que ya no era necesario el cambio de sexo en el registro para la validez del matrimonio. No obstante, la regulación del proceso de rectificación registral permitirá con mayor facilidad que el matrimonio se pueda celebrar de acuerdo con el nuevo sexo que conste en el Registro.

Encontramos una sorpresiva Disposición adicional primera de modificación del artículo 7o. de la Ley 14/2006, del 26 de mayo, sobre técnicas de reproducción humana asistida, para incluir un tercer apartado que permite ahora claramente el consentimiento de la mujer casada con otra mujer a la determinación de la filiación a su favor en caso de que su pareja se someta a estas técnicas.

28 El caso del internamiento en centros penitenciarios permitiendo que puedan ingresar en prisiones de hombres o mujeres sgún la identidad de género que manifiesten socialmente (Instrucción de la Dirección General de Instituciones Penitenciarias 7/2006 TGP de 9 de marzo de 2006 sobre Integración Penitenciaria de Personas Transexuales (tras los preceptivos informes para ello). Si bien la Instrucción 1/2001, de 12 de febrero estableció como criterio de separación el de la "identidad sexual aparente", con esta nueva Instrucción de 2006 se intenta tener encuenta la identidad sicosocial de género de estas personas para evitar su exclusión con los preceptivos informes de valoración médica y sicológica, pudiendo entonces acceder a módulos y condiciones de internamiento adecuados a su condición. Asimismo se reconoce con la misma el acceso a servicios especializados de salud para el proceso de transexualización y tratamiento endocrinológico bajo supervisión médica. Y lo más curioso e importante con relación a la Ley aquí analizada, señala que "la administración instará el empleo de nombre adecuado a su identidad y género, en las relaciones grupales e interpersonales penitenciarias, con exclusión de las de carácter oficial, incluida la documental, en que seguirá empleándose el nombre oficialmente acreditado".

29 Artículo 5o. del Real Decreto 2002/1979, de 20 de julio: "el documento nacional de identidad llevará incorporada la fotografía del rostro del titular, de frente, y con la cabeza descubierta...".

30 Artículo 16 del real Decreto 1064/1988: "dos fotografías del titular, tamaño carnet, en blanco y negro o color, en posición de frente y descubierto, midiendo la parte correspondiente al rostro un mínimo de dos centímetro de alto por uno y medio de ancho". 
nales, llevaran la cabeza cubierta con el hiyab, con base en fuentes consultadas del Ministerio del Interior se ha confirmado que, por la vía de hecho, se admiten las fotos con pañuelo islámico tanto para el DNI como para la obtención del pasaporte o de la tarjeta de identificación de extranjeros. ${ }^{31}$

Esta Ley 13/2007, de 15 de marzo, también contempla el cambio del nombre propio según el tenor literal: para que no resulte discordante con el sexo reclamado, aunque acto seguido establece, como toda regla general, una excepción en un artículo posterior: salvo cuando la persona quiera conservar el que ostente y éste no sea contrario a los requisitos establecidos en la Ley del Registro Civil. ${ }^{32}$ Un defecto de técnica legislativa observable en muchos otros puntos, como, a título ejemplificativo, la inexistencia de un inicial artículo donde se exprese el objeto de la Ley (mencionado en la exposición de motivos), y comience su articulado por la legitimación, en la que también se mencionan otras cuestiones tales como la solicitud de petición del traslado total del folio registral, que nada tiene que ver con la misma.

Aun así, cabe recibir con agrado cualquier modificación con repercusiones en el ámbito civil de tal trascendencia, no sólo por los beneficios de la misma, sino por la reticencia a los cambios, pese a la perpetuación de discriminaciones, como ha demostrado en épocas recientes y aún mantiene a título ejemplificativo con la discriminación en la elección del nombre, otorgándose preferencia al varón sobre la mujer. ${ }^{33}$

31 Motilla, A., "El problema del velo islámico en Europa y en España", Anuario de Derecho Eclesiástico del Estado, vol. XX, 2004, p. 127. Aprovechamos para realizar un breve comentario sobre la situación en la que viven muchas mujeres, pues incluso para aparecer en la foto del carnet de conducir, las mujeres prisioneras bajo el burka no se lo pueden quitar, lo que resulta problemático a la hora de pensar dicha situación en el caso de las fotos para visados, pasaportes, documento nacional de identidad, etcétera. Es decir, el uso del hiyab u otros, pueden afectar a aspectos relacionados con potestades administrativas de protección de la seguridad ciudadana con relación a la identificación de las personas a nivel internacional: El País, 30 de mayo de 2004. Carnet de conducir de una mujer musulmana expedido en Zagreb, capital de Croacia bajo las vestimentas del burka.

32 Artículo 2.1, párrafo 2.

33 A pesar de que el primer objetivo que pretendía conseguir el legislador español con la elaboración de la Ley 40/1999, la cual era eliminar de la regulación relativa a los apellidos todo vestigio de discriminación por razón de sexo, la redacción del artículo 109 del Código Civil quedó redactado de modo que, si la filiación está determinada respecto de ambas líneas, exista la posibilidad de que los padres, de común acuerdo, puedan deci- 
El artículo 3o. declara que la competencia para de las solicitudes de rectificación registral de la mención del sexo corresponderá al encargado del Registro Civil (que es un juez de primera instancia) del domicilio del solicitante, pues la posibilidad de que tuvieran competencia los registros consulares o central no tuvo éxito en la tramitación de la Ley, pese a la existencia de varias enmiendas solicitando su inclusión, lo que puede parecer razonable por parte del legislador al mantener el mismo criterio que para el cambio de nombre. Este funcionario debe calificar la capacidad de la persona transexual, y la incoación del expediente se notifica al Ministerio Fiscal quien es oído (según las reglas generales del artículo 97 LRC) y emite un informe (artículo 348 RRC), pudiendo proponer diligencias, aunque no es necesario su dictamen favorable. Se sigue, pues, el expediente gubernativo ${ }^{34}$ que permite la rectificación sin necesidad de sentencia judicial firme (rectificación encuadrada en el artículo 93.2

dir el orden de transmisión de su respectivo primer apellido antes de la inscripción registral. Pero a falta de acuerdo, prevalece la filiación paterna, ya que si no se ejercita esa opción, el primer apellido de un español es el primero del padre. Es decir, pese a la reforma operada, si el no ejercicio en la modificación del orden de los apellidos se debe a la mera inactividad de los padres, o por la falta de acuerdo, o la existencia de un conflicto entre ellos, el hijo/a será inscrito según el sistema habitual sin que la madre pueda recurrir la decisión impuesta por el padre, situación que por otra parte es avalada por gran parte de la doctrina especializada en la materia. De este modo, continúa privilegiándose que el primer apellido sea el paterno, y que prevalezca la voluntad del padre sobre el de la madre. Alguna alternativa para posibilitar que esta decisión fuera igualitaria entre los padres, sería la decisión judicial, por ejemplo, como la mejor fórmula de resolver la discrepancia de los padres tal y como se realiza en otros casos que igualmente pertenecen al derecho de familia. Otra posible solución sería la exigencia de que el acuerdo escrito y firmado por ambos progenitores se presentase ante el encargado del registro en el momento de la inscripción o bien que se requiriese la presencia de los dos progenitores en dicho momento, pues en la mujer suele estar aún convaleciente del parto. En todo caso, en el no acuerdo también para esta reforma, ha triunfado — por ahora- la preferencia del varón.

34 Cabe señalar que a pesar de dicha denominación sigue siendo, al menos en sus inicios, un procedimiento judicial, puesto que es un juez encargado del Registro Civil el que dicta dicha resolución, aunque en última instancia, cabe apelación contra sus resoluciones ante la Dirección General dependiente del Ministerio de Justicia (Poder Ejecutivo), tal vez por ello su denominación. Tanto la DGRN (a título ejemplificativo: Resolución de 17 de marzo de 1982) como el Tribunal Superior, mantuvieron sin fisuras hasta esta Ley, la imposibilidad de su realización a través de expediente gubernativo: Bustos Moreno, Y. B., op. cit., nota 24, pp. 182 y 185. 
LRC). Finalmente el Encargado del Registro Civil dicta auto, y con ello pone fin al expediente.

La incoación del expediente habrá de comunicarse a los "interesados", a los meros efectos de que realicen las manifestaciones que consideren oportunas. En relación con esto último, pensemos en el cónyuge del transexual y en los hijos que éste tuviera, pues los asientos donde conste el matrimonio y el nacimiento de los hijos se verán afectados. Al respecto también, no por obvio debe dejarse sin precisar que las relaciones familiares no se deben ver afectadas, me refiero a las de carácter matrimonial o paterno-filiales. Hoy en día ya no constituye ningún problema jurídico el tener dos madres o dos padres, y por ello tampoco a la titularidad ni ejercicio de la patria potestad. Asimismo, la introducción en el testamento de una cláusula en la que, aun respetando la intangibilidad de la legítima, condicionara la institución de heredero de ese hijo a que no cambie de sexo, sería ilícita por atentar, entre otros principios constitucionales, contra el libre desarrollo de la personalidad y habría de tenerse por no puesta, y lo mismo si fuera la condición que se hubiera impuesto para poder heredar o recibir en legado. Y en relación al vínculo matrimonial, debe señalarse que fue solicitada su ausencia en la tramitación parlamentaria de esta Ley, pero finalmente no prosperó. ${ }^{35}$

La resolución que acuerde la rectificación de la mención registral del sexo tendrá efectos constitutivos a partir de su inscripción en el Registro Civil, pudiendo incluir en la solicitud, la persona interesada, la petición del traslado total del folio registral (cancelando totalmente el antiguo asiento y procediéndose a la extensión de uno nuevo), preservando así en mayor medida su intimidad. Con esta medida se evita crear "marcas de nacimiento" igual que los títulos nobiliarios que también hasta fecha reciente era un símbolo más de la difícil clasificación binaria mujer/hombre que devenía indefectiblemente en menos derechos para las mujeres que para los hombres desde el nacimiento. ${ }^{36}$ Finalmente cabe mencionar

35 Enmiendas: BOCG Congreso de los Diputados, del 10 de octubre de 2006, serie A, núm. 89-7, p. 57, y BOCG Senado, serie II, 14 de diciembre de 2006, núm. 79, p. 9.

36 Nos remitimos a lo ya señalado en Ricoy Casas, R. M., "La sucesión de la mujer en los títulos nobiliarios. Especial referencia a la STC 126/1997, de 3 de julio de 1997", Anuario de la Facultad de Derecho de la Universidad de Vigo, 2005, artículo que ha de complementarse con la posterior Ley 33/2006, de 30 de octubre, sobre igualdad del hombre y la mujer en el orden de sucesión a los títulos nobiliarios que ha reformado esta materia. 
el positivo hecho de que, con la reexpedición del DNI, títulos académicos y demás documentos, la atención del legislador a la causa transexual ha descendido hasta el punto de regular la exención de tasas por dichos conceptos.

Hasta ahora, se condenaba a estas personas a un procedimiento judicial costoso, paliado con esta Ley junto con la agilización de su reconocimiento jurídico. Y es que, el Tribunal Supremo (TS) venía reconociendo (con votos particulares en contra) este derecho a quienes acreditasen cirugía total de reasignación sexual (al menos en su apariencia externa). ${ }^{37}$ A partir de la sentencia del TS de 17 de septiembre de 2007, este Tribunal realizó un giro jurisprudencial, ante una pretensión que había sido denegada sucesivamente en las dos sentencias de instancia, precisamente por no haberse producido la cirugía de reasignación de sexo que hasta la vigencia de la Ley 3/2007 se entendía como requisito necesario, y coherente en este punto con la doctrina del Tribunal Europeo de Derechos Humanos. ${ }^{38} \mathrm{Ha}$ de tenerse en cuenta que ya se habían producido decisiones judiciales, no revisadas por el propio TS, en las que se llegó a admitir el cambio de sexo sin realizarse una cirugía de reasignación. ${ }^{39}$ Una de las

37 Sentencias del Tribunal Supremo: 1a., 2.7.1987 (RJ 1987\5045), 15.7.1988 (RJ 1988\5722), 3.3.1989 (RJ 1989\1993) y 19.4.1991 (RJ 1991\2725). El TS llegó a impedir un cambio de sexo femenino a masculino por no cumplir la totalidad de la cirugía de reasignación, pese a que la solicitante llevaba ya más de tres años de tratamiento y había sido sometida a una primera intervención de extirpación de mamas: STS, 1a., 6.9.2002. Incluso se siguió este criterio ante la alegación de imposibilidad médica para la realización de la implantación de pene y al hecho de haberse ya sometido a mastectomía e histerectomía (SAP Valencia 30.12.2003); otra en la que la demandante alegaba no poder ser obligada a la cirugía por el riesgo que comportaba para su salud (SAP Barcelona 6.5.2002); o falta de la última fase de reasignación, no realizada por problemas económicos (SAP Madrid 15.7.2004).

38 El propio Tribunal afirmó: "la necesidad de una intervención quirúrgica de reasignación no parece justificada como presupuesto de una modificación del tratamiento de la persona interesada que, ciertamente, se presenta como afectada por un síndrome, por un estado patológico que exige un tratamiento que, obsérvese, no se dirige a corregir la tendencia hacia el sexo fenotípico o genotípico, sino hacia el síquico o anímico, tratando de aproximar el soma hacia la psique, y no a la inversa".

39 Entre otras, tal vez pudo haberse referido a las sentencias: SAP Pontevedra 27.9.2003 (JUR 2006\26139) se aparta del criterio del TS marcando las diferencias del caso concreto (dos pasos ya realizados y no únicamente el primero) y estima la rectificación, teniendo en cuenta especialmente el carácter irreversible de la cirugía ya realizada y que la demandante estaba ya en lista de espera para la faloplastia; SAP Cádiz, Ceuta 
primeras sentencias de audiencia que aplicó la nueva Ley a un caso que ya se estaba tramitando judicialmente, fue la de Córdoba en ese mismo mes de marzo de 2007.40

Casos como éste, nos muestran hasta qué punto la moral y el derecho se ven estrechamente relacionados. Baste recordar las decisiones del Tribunal Supremo durante los últimos 50 años en materia de escándalo público, concretamente en relación a la utilización de bikinis y escotes. El cotejo de estas decisiones permite observar que, en un espacio relativamente breve de tiempo, unos mismos hechos que son sancionados por el derecho como atentados graves a la moral pública, pasen luego al dominio de las elecciones morales personales sin trascendencia jurídica, y deriven a la postre en meros hábitos o costumbres sujetos a la dinámica de los usos sociales.

Existía gran preocupación por parte de nuestra máxima instancia jurisdiccional por edificarnos moralmente, como se desprende de su condena de la publicación de "una fotografía de una artista de cine con un escote tan ancho a la par que tan largo, que permite ver gran parte de su

20.4.2005 (JUR 2005\143363), que reconoce el cambio pese a estar todavía pendiente, citando expresamente motivos económicos, de faloplastia. En el mismo sentido, SSAP Valladolid 23.5.2005 (AC 2005\1549) y Jaén 9.10.2006 (JUR 2007\145216). La SAPBarcelona 17.2.2004 (AC 2004\893), pese a desestimar el cambio de sexo por no acreditación de la extirpación de útero y ovarios, admite, no obstante, y manifestándose en contra de la posición del Ministerio Fiscal, la no necesidad de faloplastia (FJ 2). Asimismo en muchos casos se diferenciaba la cirugía según fuera hombre o mujer, pues si era cirugía de hombre a mujer, sí se exigía cirugía total, y sin embargo, en el supuesto contrario, no existía una posición común, habiendo resoluciones que exigían, para estimar las demandas de cambio de sexo, no sólo que el demandante se hubiera sometido a intervenciones quirúrgicas de mastectomía e histerectomía (que suprimían los caracteres físicos femeninos), sino además, la implantación del aparato sexual masculino, aun cuando dicha intervención no pudiera llevarse a cabo por problemas ajenos a la voluntad del solicitante (como el grave riesgo para su vida: a título ejemplificativo: SAP Valencia, 30 de diciembre de 2003. De forma similar: SAP Madrid, 23 de diciembre de 2004; SAP Barcelona, 1 de septiembre de 2005; SAP Asturias, 25 de septiembre de 2006. En otras, sin embargo, se entendió que la extirpación de los caracteres sexuales primarios femeninos (ovarios, trompas, útero), además de la mastectomía bilateral, demostraba la seriedad de la petición de rectificación registral y la condición irreversible del proceso de reasignación sexual iniciado, en muchas de las cuales se alegaban consideraciones de carácter económico, laboral y médicas: A título ejemplificativo: SAP Valladolid, 23 de mayo de 2005; SAP Cádiz, 20 de abril de 2005.

40 SAP Córdoba, 27.3.2007. 
seno", así como otra de una artista "desnuda de medio cuerpo hacia arriba, cubierta simplemente con un escasísimo sostén estampado que permite ver por encima y por debajo de esa prenda lo que incompletamente intenta ocultar", y la de la artista desnuda que se cubre "el pecho con ambos brazos enlazados sobre él, teniendo un reloj de pulsera en la muñeca". Considerandos que, como señala con humor Pérez Luño, revelan una sutil y exhaustiva perspicacia observadora por parte del juzgador, al describir tan minuciosamente estas imágenes lúbricas, además de concebir al Tribunal Supremo de la etapa franquista como un auténtico "martín de bikinis" no menos contundente que lo fuera Trento para los herejes. Un amplio elenco de decisiones que se hallan dirigidas a castigar la utilización de esta "abominable" prenda, que tan directamente atenta a las convicciones del juzgador que incluso se resiste a utilizar su nombre, empleando para aludir a ella rebuscados y peregrinos circunloquios y perífrasis. ${ }^{41}$

Sólo dos años más tarde, el mismo Tribunal calificó al bikini de mero "aspecto de liviandad en las costumbres". ${ }^{2}$ Asimismo afirma que

con referencia a ese atuendo femenino - traje de baño de dos prendas- denominado con el neologismo aceptado en el lenguaje usual de "bikini", con que aparecen las mujeres de las dos fotografías... no es posible desconocer que se utiliza públicamente no sólo a diario durante las temporadas de baño, sino también en espectáculos públicos, películas cinematográficas y en la prensa; por lo que siendo indudable, aunque censurable en puros principios de moral, que la sociedad viene admitiendo y tolerando desde hace algunos años el uso público de tan trivial atuendo femenino, no puede considerarse que las fotografías insertas en la referida publicación constituyan una ofensa a la moral. ${ }^{43}$

41 CA-8-2-69/Arz. 449). En relación con estas cuestiones he seguido algunos comentarios de Pérez Luño, A. E., Teoría del derecho. Una concepción de la experiencia jurídica, Madrid, Tecnos, 1997, pp. 145 y 146.

42 P-3-7-71/Arz.3434.

43 CA-26-2-70/Arz.994. La sentencia de julio de 1986 del juzgado número uno de la Audiencia de Palma de Mallorca falló, desestimando, una demanda de atentado contra el derecho a la intimidad y a la propia imagen presentada por una mujer frente a la agencia de prensa que había publicado su foto en top-less, tomada en la playa sin su consentimiento. 
En este sentido, también autoras como Simone de Beauvoir en El segundo sexo ${ }^{44} \mathrm{o}$ Betty Friedman en La mística de la feminidad, ${ }^{45}$ hace más de 40 años, afirmaron que la medicina y sexología son ciencias, pero igual que todas, y en todas las etapas históricas, impregnadas de sesgos ideológicos que en ocasiones no responden en avanzar en el conocimiento de la realidad, sino en el control de esa realidad con base en los supuestos ideológicos que pretenden. Así, alguna autora ha llegado a afirmar que, sacar conclusiones de las deficitarias investigaciones cientificas sobre el cerebro en relación con esta cuestión (en qué parte del cerebro o qué sustancia es la que desarrolla nuestra identidad sexual) producen sonrojo intelectual. ${ }^{46}$

Finalmente se ha apostado por el criterio legal a favor del sexo sicosocial, con lo que se elimina la necesidad de cirugía de reasignación total, exigida por el Tribunal Supremo, pudiendo considerarse como un considerable avance. Interpretación hacia la psique que ya habían sido manifestadas por la Recomendación 1117/1989 del Consejo de Europa, o incluso ser una de las consideraciones por el Diccionario de la Lengua Española) al definir al transexual como una "persona que se siente del otro sexo y adopta sus atuendos y comportamientos" o "la que mediante tratamiento hormonal e intervención quirúrgica adquiere los caracteres sexuales del sexo opuesto". ${ }^{47}$

No se exige por lo tanto cirugía, pero sí es necesario acreditar tratamiento durante dos años, ${ }^{48}$ por parte médico. Una exigencia legal que puede servir de medida disuasoria a la automedicación de hormonas, que provoca un incremento notable de los riesgos relacionados con este tratamiento. Muchos consideran pues que se encuentran "presos de su cuerpo" por imperativo legal, al preguntarse ¿por qué no llega ya con todo lo que han tenido que padecer y hay que someterlos y que esperen

44 De Beauvoir, S., El segundo sexo, Madrid, Cátedra-Instituto de la Mujer, 2000.

45 Friedam, B., La mística de la feminidad, Madrid, Biblioteca Júcar, 1974.

46 Campos, A., op. cit., nota 8.

47 En ese sentido, ya se había manifestado el Tribunal Superior de Justicia de Asturias afirmando que los conceptos de transexualidad e intersexualidad son conceptos médicos, no jurídicos, debiendo de acudirse al punto de vista médico para su definición: Tribunal Superior de Justicia de Asturias (sala de lo social), sentencia del 31 de enero de 2003.

48 Los especialistas en la materia afirman que posprimeros efectos hormonales se perciben ya entre la sexta y octava semana, completándose los cambios, aproximadamente entre seis y cuatro meses. 
dos años de tratamiento? ¿Debería dejarse a su propia elección, dentro de la pura esfera personal? ¿Hasta qué punto intervenirse? Ha de señalarse a favor de esta ley que estos tratamientos médicos no son un requisito necesario para la concesión de la rectificación registral cuando concurran razones de salud o edad que imposibilitan su seguimiento y se aporta certificación médica de tal circunstancia. Pero cabe otra objeción final: ¿y por razones económicas?

Asimismo, esta Ley ha optado por no incluir ninguna precisión sobre la necesidad de esterilización, otra cosa es que la viabilidad fáctica pueda venir constreñida cuando los órganos reproductores del transexual hayan quedado dañados a consecuencia del tratamiento hormonal y/o quirúrgico de reasignación. Pero dificultad no es imposibilidad, máxime con las posibilidades que ampara la Ley 14/2006, de 26 de mayo, sobre técnicas de reproducción humana asistida. Posibilidad hecha realidad en Estados Unidos y sobre la que ya existe también un caso en España.

Partiendo de la idea de que la cirugía de cambio de sexo está despenalizada por el artículo 428.2,49 cuando exista "consentimiento libre y expreso del afectado" - artículo trasladado casi literalmente al artículo 156.1 del vigente Código Penal de 1995 (a mayor de edad con consentimiento personalísimo y emitido consciente y libremente)-, una de las preguntas que se plantean es la de ¿por qué esperar a la mayoría de edad para poder realizarla? Entre otras razones, tal cuestión resulta de probado fundamento si tenemos en cuenta que constituye una excepción a lo que suele ser habitual en materia de derechos de la personalidad, y porque se exige informe médico para acreditar su carácter permanente y estable durante un periodo mínimo de dos años.

Asimismo sorprende por el curioso consenso concerniente a los atletas que habían realizado cambio de sexo, elaborado por la Comisión Ejecutiva del Comité Internacional Olímpico el 17 de mayo de 2004 con motivo de los Juegos Olímpicos XXVIII celebrados en Atenas. El mismo disponía que todo hombre que hubiera seguido una operación de cambio de sexo antes de la pubertad, había de ser considerado como del sexo femenino, y lo mismo a las mujeres a la inversa. Por eso coincido con Elósegui Itxaso cuando asevera que resulta bastante curioso desde el punto de vista médico y jurídico. En cuando a la perspectiva jurídica, porque no existe ninguna legislación en ningún país del mundo que per-

49 El mismo ha sido introducido por la LO 8/1983, de 25 de junio. 
mita la operación de la cirugía de cambio de sexo antes de los 18 años. De esta manera, es prácticamente inviable encontrarse con una persona que haya sido operada antes de la pubertad, salvo que se haya hecho contra derecho y transgrediendo las normas jurídicas del país en el que dicha operación se haya realizado. ${ }^{50}$

Y ello, a diferencia de los casos de reasignación genital reparadora en estados intersexuales patológicos (casos de hermafroditismo o seudo-hermafroditismo), realizados desde el nacimiento y en la pubertad, asumidas por la Sanidad Pública por venir incluidas en el catálogo de prestaciones del catálogo del Sistema Nacional de Salud. ${ }^{51}$ En ese sentido, la Ley sueca de 21 de abril de 1972 permite a la autoridad administrativa competente modificar registralmente el sexo de la persona que desde la adolescencia haya advertido que no pertenece al sexo recogido en el Registro. ${ }^{52}$

En un estudio realizado en 200 pacientes pertenecientes a la Unidad de Transtornos de Identidad de Género del Hospital Carlos Haya de Málaga, la edad estimada a la que pensaron, por primera vez, con intensidad, que querían pertenecer al sexo opuesto es de 9.51 años, para el grupo hombre a mujer, y a los 8.85 años, para el grupo mujer a hombre. Todos los pacientes hombre a mujer del estudio refieren que desearon adoptar el aspecto físico de una mujer, por primera vez, con una media de edad estimada de 14.20 años. Se establece de forma definitiva este deseo a $\operatorname{los} 16.27$ años. ${ }^{53}$

Algunos especialistas consideran que puede iniciarse tratamiento hormonal reversible, siempre previa autorización de padres o tutores, para frenar los cambios puberales y facilitar así los cambios tras la reasignación sexual, en caso de confirmarse el diagnóstico. Este tratamiento bloquea el desarrollo de las características sexuales secundarias sin inducir las características del otro sexo (por ejemplo, mamas en niños o barba o voz profunda en niñas). Los transexuales que precisan reasignación a mujer resultan beneficiados si no ha aparecido la barba o no desarrollan

50 Elósegui Itxaso, M., "El consenso del Comité Olímpico sobre atletas que han cambiado de sexo", Revista Jurídica del Deporte, núm. 13, 2005, p. 97.

51 Bustos Moreno, Y. B., op. cit., nota 24, p. 64.

52 López-Galiacho Perona, J., La problemática jurídica de la transexualidad, Madrid, 1998, p. 151.

53 Cano Oncala, G., "La construcción de la identidad de género en pacientes transexuales", Revista de la Asociación Española de Neuropsiquiatría, 2004, vol. 24, núm. 89, pp. 2841 y 2842. 
una voz profunda. En caso de mujer que precisa reasignación a hombre, el tratamiento hormonal precoz favorecería a que, al desarrollarse menos las mamas, la mastectomía posterior sea una intervención más fácil y con menos cicatrices. En ambos casos, los adolescentes que han sido tratados precozmente presentarán un fenotipo final mucho más acorde con el del sexo que se identifican. ${ }^{54}$

Desde el prisma jurídico, es necesario plantearse la forma de prestar el consentimiento informado a dichos tratamientos al tratarse de menores de edad, aunque con 16 años cumplidos. La profesora Bustos Moreno afirma que, si bien es cierto que no se permite que los menores de edad, ni sus representantes legales, puedan consentir la cirugía transexual, la hormonización del transexual adolescente es médicamete posible y aconsejable para el menor, en ciertos casos, debidamente diagnosticados. La cuestion es si legalmente éstos podrían decidir solos o deberán actuar con el consentimiento de sus representantes legales. De forma expresa no se dice nada en ningún texto legal, por lo que cabe interpretar que es lícita la hormonización del transexual mayor de dieciséis años, y además deber ser consentida por éste, en aplicación del genérico artículo 9.3 de la Ley 41/2002: 9.3 c), "cuando se trate de menores no incapaces ni incapacitados, pero emancipados o con dieciséis años cumplidos, no cabe prestar el consentimiento por representación". Sin embargo, en caso de actuación de grave riesgo, según el criterio del facultativo, los padres serán informados y su opinión será tenida en cuenta para la toma de la decisión correspondiente.

Así, además de la diagnosis, se exige el tratamiento médico de adecuación de las características físicas al sexo reclamado, el cual, no obstante, queda ahora sin un contenido predeterminado, porque no se aporta un contenido mínimo para ninguno de los casos posibles, abriendo la puerta al casuismo máximo, que algunos observarán como positivo, precisamente para poder adaptar la aplicación de la ley a cada caso concreto, pero no exento de peligros.

Ya han sido expuestos algunos requisitos de legitimación: el de la mayoría de edad, y el de capacidad suficiente. Con la necesidad de ostentar la nacionalidad española, se ha excluido de su aplicación a los extranje-

54 Bustos Moreno, Y. B., op. cit., nota 24, pp. 66 y 67, siguiendo a Otero Camprubí, A. y Gómez Gil, E., "Transtornos sexuales. Tanstornos de la identidad de género", Tratado de psiquiatría, Barcelona, 2005, vol. II, p. 1556. 
ros, incluso con residencia en España. Y ello, pese a la resolución de 24 de enero de 2005 que había admitido la competencia de los tribunales españoles para proceder al cambio de sexo de un extranjero transexual con residencia habitual en España a pesar de que el país del que era nacional no admitía tal modificación, y reconoció el derecho del mismo a obtener una autorización de matrimonio civil con persona del mismo sexo biológico y la inscripción registral de tal matrimonio, con anterioridad a la reforma del artículo 44 del Código Civil introducida por la Ley 13/2005.55 Ha de destacarse, no obstante, que no se ha llegado ni siquiera a favorecer el reconocimiento mutuo entre Estados, a pesar de ser estas cuestiones unas de las más controvertidas en la discusión parlamentaria de esta Ley, lo que visibiliza las dificultades que los transexuales encuentran para el reconocimiento sobre el plano internacional de las decisiones de cambio de sexo. Por extensión se excluye a los apátridas o refugiados, y sin embargo se ha permitido que se otorgue el derecho de asilo a las mujeres lesbianas y transexuales extranjeras que cumplan los presupuestos legales establecidos al efecto. ${ }^{56}$

Quizás deberíamos estar ya en una situación social y jurídica en la que tomase ya realidad la irrelevancia del sexo en el tráfico jurídico, puesto que hasta la Ley 13/2005, del 1o. de julio, por la que se modifica el Código Civil en materia de derecho a contraer matrimonio, podía sostenerse que el sexo era una cualidad que servía de base a otros estados civiles, pensando en el matrimonio y en la filiación, pero actualmente el sexo todavía continúa teniendo alcance jurídico, contribuye a la identificación de la persona y figura en el Registro Civil en diversos documentos administrativos relevantes a este respecto, como el documento nacional de identidad. También resulta importante en varias discriminaciones que se siguen produciendo en el ordenamiento jurídico español: para establecer el orden de transmisión de los apellidos en la filiación determinada por ambas líneas cuando los progenitores sean de distinto sexo en caso de silencio o desacuerdo entre ellos según lo ya expuesto, en el orden a suceder en la Corona española (artículo 57.1), o la práctica del deporte en competición. Y hasta hace muy poco, cambiado, afortunadamente, para

55 Sentencia del Juzgado de Primera Instancia núm. 40 de Barcelona de 24 de enero de 2005, FD 9.

56 Bustos Moreno, Y. B., op. cit., nota 24, pp. 230-236. 
el acceso a determinados cuerpos profesionales como prisiones o en la propia sucesión a los títulos nobiliarios, por poner algún ejemplo.

Precisamente como afirmaron en su voto particular en una sentencia relativa a la discriminación en la sucesión a los títulos nobiliarios los magistrados Carles Viver Pi-Sunyer y Tomás S. Vives Antón trasladable a los argumentos señalados, no puede relativizarse esta cuestión por el escaso pero importante número de personas afectadas, ni a la creencia de su escasa virtualidad jurídica o social, pues el valor de los derechos fundamentales no se mide por el número de sus posibles titulares ni por el mayor o menor alcance de sus consecuencias jurídicas y prácticas. Los datos cuantitativos no pueden convertirse en canon para determinar la vulneración o no de una prohibición expresa de discriminación como la relativa al sexo. La prohibición que contiene el artículo $14 \mathrm{CE}$ determina la radical exclusión de cualquier modulación en el estatus de estos ciudadanos respecto del resto, tanto individual como colegiadamente. ${ }^{57}$

Tal vez también sea un debate abierto resumido en la cuestión: ¿más derechos a los transexuales? La que parece lejana jurisprudencia del TS que ya comenzaba acceder a la rectificación del sexo en casos de transexualidad (como las sentencias del 2 de julio de 1987, 15 de julio de 1988 y 3 de marzo de 1989, a título ejemplificativo), fueron criticadas por la doctrina, pese a su ambición, al no acceder a reconocimiento de las consecuencias de las mismas. Así, autores como Martínez Pereda afirmaban que se trataba de un cambio de sexo "ma non tropo", descafeinado y que el Tribunal Superior lo que ha creado es un "tertius sexus", femenino, pero no totalmente, al menos en sus efectos jurídicos. ${ }^{58}$ Otros consideran que al aceptar el planteamiento de considerar al sexo como un verdadero estado civil, y teniendo a la vista las resoluciones del Tribunal Supremo

57 STC 126/1997 de 3 de julio de 1997, que establece la actual preferencia del varón sobre la mujer en igualdad de línea y grado, en la sucesión a los títulos nobiliarios. Presidente: Álvaro Rodríguez Bereijo; magistrado ponente: Julio Diego González Campos; Magistrados: José Gabaldón López, Fernando García-Mon y González-Regueral, Vicente Gimeno Sendra, Rafael de Mendizábal Allende, Enrique Ruiz Vadillo, Manuel Jiménez de Parga y Cabrera, Pablo García Manzano, Carles Viver Pi-Sunyer, Tomás S. Vives Antón y Pedro Cruz Villalón. Estos tres últimos se apartaron de la argumentación y del fallo defendido por la mayoría, manifestando su opinión contraria a ésta en dos votos particulares, el segundo formulado por el último magistrado mencionado, y el primero por los dos anteriores a éste.

58 Martínez Pereda, AC, "El transexualismo en el derecho español, otras sentencias del Tribunal Supermo sobre el cambio de sexo", Actualidad Civil, núm. 46, 1990, p. 739. 
no quedaría más remedio que aceptar, en relación al sexo, tres estados civiles: el de mujer, el de hombre y el de transexual. ${ }^{59} \mathrm{Y}$ siguiendo esta línea, hay quien considera que los dos primeros tendrían relevancia para el ordenamiento jurídico, pero no supondrían limitación de la capacidad de obrar, en cambio, el tercero afectaría a la capacidad de obrar, tal y como plantea nuestra jurisprudencia. ${ }^{60}$

Quizás el optimismo pueda venir recordando los logros que ha conseguido la mujer en este ámbito a lo largo de las últimas décadas. Por poner ejemplos relacionados con la temática aquí tratada, debemos recordar que su condición de mujer y ya en el ámbito jurídico, condenó durante un tiempo al anonimato a Concepción Arenal, quien acudía disfrazada con indumentaria masculina como oyente a las clases de derecho en la Universidad Complutense de Madrid, al estar prohibido el acceso a la Universidad a las mujeres. ${ }^{61}$ Incluso, vestía de caballero para participar en las tertulias políticas y literarias y obtener así la complacencia de un público que, de conocer su condición de mujer, no habría acudido, y a la vez rechazando con ello, la tradicional concepción que se tenía de la mujer en esa época. ${ }^{62}$ Anteriormente a ella, la baronesa Dudevant, más conocida por el seudónimo adoptado, George Sand, ya utilizaba de forma habitual la indumentaria masculina.

Asimismo, aunque no existía ninguna ley que lo prohibiese, el caso de Cecilia Böhl de Faber y Larrea fue muy común; una escritora romántica que se escondió tras un seudónimo masculino; "Fernán Caballero", e igual que Matilde Cherner; "Rafael de Luna", o el de la escritora María de Lejárraga, quien durante años pasó por colaboradora de su marido; el dramaturgo Gregorio Martínez Sierra, a pesar de haber sido ella la autora de casi todo el teatro de éste - unas 50 obras - algunas de gran éxito como "canción de cuna". También existían otras modalidades para conseguir ocultar un nombre femenino con poder creativo con el "de" (apos-

59 Díez del Corral Rivas, J., "Estado civil y sexo. Transexualidad”, Actualidad Civil, núm. 36, 1987, pp. 2155.

60 Gómez Laplaza, C., Transexualidad, Aranzadi Civil, 2004, núm. 1, p. 24.

61 Hasta 1910, la mujer ni siquiera tenía acceso a la Universidad en España, precisándose no obstante periplos ocurridos previamente a su consecución como el caso de María Elena Maseras en 1872, que fue la única y a la vez la primera mujer matriculada en la Facultad de Medicina de la Universidad de Barcelona.

62 Vales Vía, J. D., Un disfraz en las aulas, Galicia en Madrid, núm. 51, 1994, pp. 16 y 17. 
tilla con el apellido del marido) resultaba "tranquilizador"; una manera de disipar los serios recelos que inspiraba la mujer "literata", pues venía a ser la garantía de una "correcta situación familiar, aval de la sana doctrina moral que de una señora casada o viuda podía esperarse. En otros casos las ocultaciones eran parciales, por ejemplo con la supresión del primer apellido o reducido a la inicial; también los criptogramas son muy empleados utilizando las iniciales del auténtico nombre u otras composiciones; nombres de animales como "gallina ciega" o el de "colombine" de Carmen de Burgos; hacían uso de su título nobiliario o el de los maridos; seudónimos con nombres y apellidos (como el señalado de "Isabel Luna" utilizado por Matilde Cherner), o directamente nombres propios masculinos como el señalado de "Fernán Caballero" tras el que se ocultaba Cecilia Böhl de Faber y Larrea. El motivo de esta última elección fue debida a que, su tercer marido, Antonio Arrom de Ayala, se empeñó en publicar La Gaviota en París, pero luego le convencieron de que debía hacerse en Madrid. Ella se negó pero él se había comprometido ya con el ministro don Pedro de Egaña, director de El Heraldo. La convenció de que lo único que podría hacerse, si tal repugnancia tenía a ver con su verdadero nombre en letras de molde, era designar un seudónimo, lo cual había de hacer prontamente, pues no quedaba tiempo.

En este apuro, cogí unos periódicos que había sobre la mesa para buscar un nombre cualquiera que pudiese evitar al mío propio el salir a la vergüenza pública, y encontré la relación de un asesinato cometido en un pueblecillo de la Mancha llamado Fernán Caballero... Gustóme este nombre, por su sabor antiguo y caballeresco, y sin titubear un momento lo envié a Madrid, trocando para el público mis modestas faldas de Cecilia por los castizos calzones de Fernán Caballero. ${ }^{63}$

Muchas han realizado pues, grandes aportaciones cuyos méritos han sido atribuidos a otros tantos que supieron silenciar el origen de las mismas, o sin negarlo, han permitido su deshonesta adjudicación. El propio Vargas Llosa ha afirmado que ha sido en realidad la feminista, revolucionaria y anarquista abuela del pintor Paul Gauguin, Flora Tristán, la que esbozó por primera vez la idea precisa de la I Internacional a través de su

63 Simón Palmer, Ma. C., "La ocultación de la propia personalidad en las escritoras del siglo XIX", Actas del IX Congreso de la Asociación Internacional de Hispanistas, 1986, pp. 91-97. 
libro La unión obrera, que publicó en 1840, atribuida posteriormente a Carlos Marx. ${ }^{64}$

Sea como fuere, la notoriedad del caso se remonta en la historia incluso al siglo XVI. Elena de Céspedes (alias Eleno —así se nombra en los documentos-), cirujana mulata e hija de esclava a finales del siglo XVI (entre 1587 y 1588), fue motivo de dos largos y escabrosos procesos, civil e inquisitorial, uno de los casos estrella de la Inquisición española (inquisición de Toledo). Ante la Inquisición explica que es hermafrodita y que su cuerpo a lo largo de su vida se había transformado de mujer a hombre. En la determinación de sexo ordenada por el Vicario general de Madrid en 1586, dos médicos reales, peritos y de gran prestigio, afirman que Elena es varón y que tiene un miembro viril apto y perfecto con sus testículos formados como cualquier hombre. Las dudas que pudieron tener los miembros del tribunal acerca de su hermafroditismo son similares a las que, cuatro siglos después, muchos aún tienen para etiquetar a los transexuales, tal vez las mismas que sirvieron a Elena para librarse de la hoguera. ${ }^{65}$

\section{BIBLIOGRAFÍA}

BECERRA FERNÁNDEZ, A., "Atención endicronológica de la transexualidad”, en GARCÍA RUIZ, M. (coord.), Seminario Transexualidad: hom-

64 Vargas Llosa, M., El paraíso en la otra esquina, Madrid, Alfaguara, 2003. Dicha idea fue por él repetida en el Curso de Verano de la Universidad Internacional Menéndez Pelayo sobre "Flora Tristán: agitadora y feminista", celebrado en Santander del 8 al 9 de julio de 2002, que él mismo dirigió.

65 Maganto Pavón, E., El proceso inquisitorial contra Elena/o de Céspedes (15871588) (Biografía de una cirujana transexual del siglo XVI, Madrid, 2007. El fallo condenando a la acusada está escuetamente esbozado en el primer folio del legajo conservado en el Archivo Nacional: "Céspedes-Elena, alias Eleno de, natural de Alama, esclava y después libre, casó con un hombre y tuvo un hijo; desaparecido y muerto su marido se vistió de hombre y estuvo en la Guerra de los Moriscos de Granada; se examinó de cirujano y se casó con una mujer. Fue presa en Ocaña y llevada a la Inquisición, donde se le acusa y condena por desprecio al matrimonio y tener pacto con el demonio. Penitenciada a salir al Auto Público de Fe que se celebró en la Plaza de Zocodover de Toledo el domingo 18 de diciembre de 1588, al que salió en forma de penitente con coroza e insignias que manifestaban su delito; abjuró de leve y se le dieron cien azotes por las calles públicas de Toledo y otros cien por las de Ciempozuelos, reclusión de diez años en un hospital para que sirviese sin sueldo en las enfermerías". 
bres y mujeres con todos los derechos. Guía sobre la transexualidad, Principado de Asturias, 2005. disponible en http://www.cmpa.es/datos/2/GUIA_TRANSEXUALIDAD_interior_7529.pdf.

Bustos MoReno, Y. B., La transexualidad (de acuerdo a la Ley 3/2007, de 15 de marzo), Madrid, Dykinson, 2008.

BUTTLER, J., El género en disputa. El feminismo y la subversión de la identidad, México, Paidós, 2001.

CAMPOS, A., "La transexualidad y el derecho a la identidad sexual", ponencia presentada en Valencia, 2001.

CANO ONCALA, G., "La construcción de la identidad de género en pacientes transexuales", Revista de la Asociación Española de Neuropsiquiatría, vol. 24, núm. 89, 2004.

DE BEAUvoIR, S., El segundo sexo, Madrid, Cátedra-Instituto de la Mujer, 2000.

DíEZ DEL Corral Rivas, J., "Estado civil y sexo. Transexualidad", Actualidad Civil, núm. 36, 1987.

ElÓSEGui ITXASO, M., "El consenso del Comité Olímpico sobre atletas que han cambiado de sexo", Revista Jurídica del Deporte, núm. 13, 2005.

ESTEVA, I. y otros, "Epidemiología de la transexualidad en Andalucía, atención especial al grupo de adolescentes", Cuadernos de Medicina y Psicomática y Psiquiatría de Enlace, núm. 78, 2006.

FrIEDAM, B., La mística de la feminidad, Madrid, Biblioteca Júcar, 1974.

GIL RODRÍGUEZ, E. P., “¿Por qué le llaman género cuando quieren decir sexo? Una aproximación a la teoría de la performatividad de Judith Butler", Atenea Digital, núm. 2, 2002.

GÓMEZ LAPlAZA, C., "Transexualidad", Aranzadi Civil, núm. 1, 2004.

LÓPEZ-GALIACHO PERONA, J., La problemática jurídica de la transexualidad, Madrid, 1998.

MAGANTO PAVÓN, E., El proceso inquisitorial contra Elenalo de Céspedes (1587-1588) (Biografia de una cirujana transexual del siglo XVI, Madrid, 2007.

MARTÍNEZ PEREDA, A., "El transexualismo en el derecho español, otras sentencias del Tribunal Supremo sobre el cambio de sexo", Actualidad Civil, núm. 46, 1990.

Motilla, A., "El problema del velo islámico en Europa y en España", Anuario de Derecho Eclesiástico del Estado, vol. XX, 2004. 
Ollero, A., Discriminación por razón de sexo. Valores, principios y normas en la jurisprudencia constitucional española, Madrid, Centro de Estudios Políticos y Constitucionales, 1999.

OTERo CAMPRUBí, A. y GÓMEZ GiL, E., "Transtornos sexuales. Tanstornos de la identidad de género", Tratado de psiquiatría, Barcelona, 2005, vol. II. PÉREZ LuÑO, A. E., Los derechos fundamentales, Madrid, Tecnos, 1991. PRIETO SANCHÍs, L., "El sistema de protección de los derechos fundamentales: el artículo 53 de la Constitución Española", Anuario de Derechos Humanos, núm. 2, 1983.

RICOY CASAS, R. M., "La sucesión de la mujer en los títulos nobiliarios. Especial referencia a la STC 126/1997, de 3 de julio de 1997", Anuario de la Facultad de Derecho de la Universidad de Vigo, 2005.

SIMÓN PALMER, Ma. C., "La ocultación de la propia personalidad en las escritoras del siglo XIX”, Actas del IX Congreso de la Asociación Internacional de Hispanistas, 1986.

STOLKE, V., "La mujer es puro cuento: la cultura del género", Estudos Feministas, Florianópolis, 12 (2), mayo-agosto de 2004.

StOller, R. J., "Sex and Gender", Science House, Nueva York, 1968.

TUBERT, S. (ed.), Del sexo al género. Los equívocos de un concepto, Madrid, Cátedra, 2003.

VALES VÍA, J. D., "Un disfraz en las aulas”, Galicia en Madrid, núm. 51, 1994.

VARGAS LlOSA, M., El paraíso en la otra esquina, Madrid, Alfaguara, 2003. 